\title{
A novel mutation in the $D A X 1$ gene in a newborn with adrenal hypoplasia congenita in Korea
}

\author{
Juyeen Lee', Won Duck Kim*, Hae Sook Kim¹, Eun Kyung Lee', and Hyung Doo Park² \\ 'Department of Pediatrics, Daegu Fatima Hospital, Daegu, Korea \\ ${ }^{2}$ Department of Laboratory Medicine and Genetics, Samsung Medical Center, Seoul, Korea
}

\begin{abstract}
Adrenal hypoplasia congenita $(\mathrm{AHC})$ is a rare cause of adrenal insufficiency during neonatal period. Mutations in the gene coding for DAX1 cause X-linked adrenal hypoplasia. Most affected patients are shown to have salt wasting and hyperpigmentation on the skin during the neonatal period and require intensive medical care. In addition, it is usually associated with hypogonadotropic hypogonadism in adolescence. The DAX1 gene is expressed in the adrenal cortex, pituitary gland, hypothalamus, testis, and ovary. We report on a patient with genetically confirmed AHC whose initial clinical presentations were consistent with congenital adrenal hyperplasia. A point mutation in the DAX1 gene identified in this report resulted in a truncated DAX1 protein. Our patient was diagnosed with AHC.
\end{abstract}

Key words: Congenital adrenal hypoplasia, Adrenal insufficiency, Human DAX1 protein.

\section{Introduction}

Adrenal hypoplasia congenita $(\mathrm{AHC})$ is a rare lethal disorder of adrenal gland development, resulting from deletion or mutation of the DAX1 (dosage-sensitive sex reversal-AHC critical region on the $X$ chromosome gene-1) gene [1]. During the neonatal period, male patients generally show signs and symptoms indistinguishable from those seen in the salt-losing form of 21-hydroxylase deficiency (21-OHD) [2] and are frequently misdiagnosed with congenital adrenal hyperplasia (CAH). Distinguishing between these two disorders is important because they differ in clinical course and prognosis. Steroid management and genetic counseling are also different between them [3]. Recently, the $D A X 1$ gene was identified as a gene responsible for $X$-linked AHC [4]. Herein, we report on the genetic analysis of the $D A X 1$ gene in a male full-term infant with primary adrenal insufficiency.
Case

A 21-day-old male baby who presented with poor weight gain and hyperpigmentation of the skin was admitted to the neonatal intensive care unit. He was born at 40 weeks and 5 days gestation via caesarian section due to cephalopelvic disproportion. His birth weight was 3,520 g. Parents had no consanguinity and there was no family history of endocrine disease. On the day of admission, his weight was 3,570 g. His heart rate was 164 beats/ minute, respiratory rate 56 breaths/minute and blood pressure 71/32 mmHg. On physical examination, he was dehydrated with increased skin pigmentation, which was diffused in nature (Fig. 1). His body temperature was normal. On auscultation, the chest was clear with no adventitious sounds. The liver size was within normal limits and the spleen was not palpable. Abdominal, cardiovascular, and neurological examinations yielded unremark-

\footnotetext{
Received: 17 May 2017, Revised: 9 June 2017, Accepted: 9 June 2017, Published: 30 June 2017

${ }^{*}$ Corresponding author: Won Duck Kim, M.D.

Department of Pediatrics, Daegu Fatima Hospital, 99 Ayang-ro, Dong-gu, Daegu 41199, Korea.

Tel: +82-53-940-7246, Fax: +82-53-954-7417, E-mail: 0101turtle@gmail.com

Conflict of interest: The authors declare that they do not have any conflicts of interest.

(c) This is an open-access article distributed under the terms of the Creative Commons Attribution Non-Commercial License (http://creativecommons.org/licenses/by-nc/4.0/) which permits unrestricted non-commercial use, distribution, and reproduction in any medium, provided the original work is properly cited.

(c) Copyright 2017 by the Korean Society of Medical Genetics and Genomics

www.e-kjgm.org
} 
able findings. His head circumference was at the 50th percentile, weight at the 3rd percentile, and height at the 70th percentile.

Initial laboratory tests showed severe hyponatremia (sodium $120 \mathrm{mmol} / \mathrm{L}$; reference $135-153 \mathrm{mmol} / \mathrm{L}$ ), hyperkalemia (potassium $8.7 \mathrm{mmol} / \mathrm{L}$; reference $3.5-5.3 \mathrm{mmol} / \mathrm{L}$ ), elevated blood urea nitrogen level ( $46.9 \mathrm{mg} / \mathrm{dL}$; reference $3-12 \mathrm{mg} / \mathrm{dL}$ ) with low serum osmolarity (264 m0sm/kg; reference 270-310 m0sm/kg), indicating hypo-osmotic dehydration caused by salt wasting.

Further endocrine investigations were as follows: basal cortisol level, 164 nmol/L (reference 185-624 nmol/L); adrenocorticotropic hormone (ACTH) level, 2,000 pmol/L (reference 7.2-63.3 $\mathrm{pmol} / \mathrm{L}$ ); testosterone level, 1.03 mmol/L (reference 2.67-10.12 $\mathrm{mmol} / \mathrm{L}$ ); dehydroepiandrosterone sulfate level, $3.3 \mu \mathrm{mol} / \mathrm{L}$ (reference 0.96-7.8 $\mu \mathrm{mol} / \mathrm{L}$ ); aldosterone level $2.6 \mathrm{nmol} / \mathrm{L}$ (reference $5-90 \mathrm{nmol} / \mathrm{L}$ ) and plasma rennin activity, $56.41 \mathrm{ng} / \mathrm{mL} / \mathrm{hr}$ (reference $0.95-3.95 \mathrm{ng} / \mathrm{mL} / \mathrm{hr}$ ).

We carried out an ACTH stimulation test to confirm adrenal insufficiency. We measured serum cortisol levels before and after intravenous administration of synthetic ACTH (tetracosactide). A baseline or stimulated levels of cortisol higher than 600 $\mathrm{nmol} / \mathrm{L}$ indicates a physiological response by the adrenal cortex [5]. After ACTH stimulation, the maximum serum cortisol level was $117 \mathrm{nmol} / \mathrm{L}$ indicating that he had primary adrenal insufficiency.

Serum concentration of 17-alphahydroxyprogesterone (17OHP) was $4.47 \mathrm{mmol} / \mathrm{L}$ (reference 1.88-9.5 mmol/L). Serum concentration of 17-OHP is elevated in 21-OHD, but normal or low in AHC. Thus, the normal basal 17-OHP level in this infant supported the diagnosis of AHC.

Adrenal sonography showed normal findings with no hemorrhage, calcification, or other focal lesions. However, the characteristic features of congenital adrenal hypoplasia, were not ob-

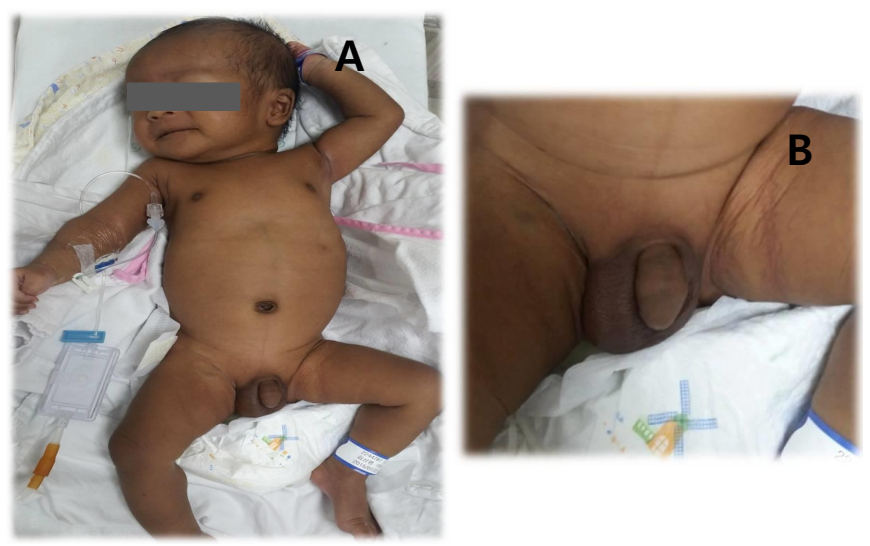

Fig. 1. Gross physical appearance. (A) Generalized hyperpigmentation of the skin. (B) Hyperpigmentation of the scrotum. served. There was no abnormality in tandem mass spectrometry.

A blood sample of the patient was sent to Samsung Medical Center Laboratory. Fluorescent in situ hybridization (FISH) analysis was performed. A molecular genetic study found a hemizygous nonsense mutation (c.273C $>A\left(p . T y r 91^{*}\right)$ ) in the DAX1 gene; therefore we diagnosed the patient with AHC (Fig. 2). The nonsense mutation (A for $\mathrm{C}$ at nucleotide 273) resulted in a stop codon at position 91. However, FISH analysis was not performed for his mother considering she could be a carrier.

The diagnosis was confirmed as AHC. Hydrocortisone, fludrocortisone, and sodium chloride supplementation were started to treat him. The patient was treated with hydrocortisone at a dose of $30 \mathrm{mg} / \mathrm{m}^{2} /$ day and fludrocortisone at $0.2 \mathrm{mg} /$ day. His potassium level was decreased to $5.9 \mathrm{mmol} / \mathrm{L}$ and sodium was elevated to $134 \mathrm{mmol} / \mathrm{L}$ after 4 days of treatment. After 3 weeks of treatment, no vomiting was reported, and the newborn tolerated feeding and demonstrated appropriate weight gain. The hyperpigmentation gradually disappeared. Since then, his serum electrolyte and hormone levels have been monitored regularly. He was discharged from the hospital when he was 45-day-old and has had regular follow-up visits through outpatient clinic since then. The patient took 3 types of medicine for AHC daily: sodium chloride ( $1 \mathrm{~g} /$ day), hydrocortisone $\left(15 \mathrm{mg} / \mathrm{m}^{2} /\right.$ day) and fludrocortisone $(0.1 \mathrm{mg} /$ day). His laboratory results including sodium and potassium level were stable. When he was 20-monthold, he visited the emergency room (ER) at Daegu Fatima Hospital with a seizure. It was his first seizure and he was afebrile. His seizure type was generalized tonic-clonic (G-T-C) and its duration was within 3 minutes. He had nausea and vomiting for 1 day before his visit to the ER. After admission, he had 3 more G-

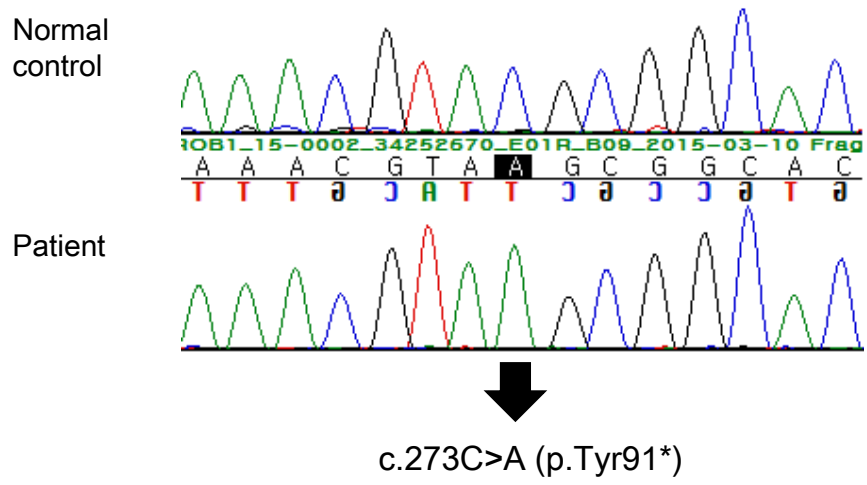

Fig. 2. Identification of a hemizygous nonsense mutation in the $D A X 1$ gene. A point mutation of c. $273 \mathrm{C}>\mathrm{A}$ leads to early termination at position 91 in the dosage-sensitive sex reversal adrenal hypoplasia critical region on chromosome $X$, gene 1 (DAX1). 
T-C type seizures and after injection of intravenous lorazepam $(0.1 \mathrm{mg} / \mathrm{kg})$, the seizures stopped. He was drowsy after the seizures. The laboratory tests showed hyponatremia (sodium 120 $\mathrm{mmol} / \mathrm{L}$; reference 135-153 mmol/L), hyperkalemia (potassium $5.5 \mathrm{mmol} / \mathrm{L}$; reference $3.5-5.3 \mathrm{mmol} / \mathrm{L}$ ). He was treated with $3 \%$ sodium chloride infusion and his sodium chloride level became within normal range after 24 hours. He was also treated with an increased dose of hydrocortisone $\left(45 \mathrm{mg} / \mathrm{m}^{2} /\right.$ day) for the adrenal crisis. We did not conduct electroencephalography or brain magnetic resonance imaging because we thought his seizures were due to severe hyponatremia, and correction of hyponatremia stopped the seizures. Two weeks after the first adrenal crisis, he became lethargic again due to vomiting and poor oral intake. He was re-admitted. The laboratory tests showed severe hyponatremia (sodium $116 \mathrm{mmol} / \mathrm{L}$; reference $135-153 \mathrm{mmol} / \mathrm{L}$ ) and hyperkalemia (potassium $5.5 \mathrm{mmol} / \mathrm{L}$; reference $3.5-5.3 \mathrm{mmol} /$ L). This was his second adrenal crisis and after the treatment, he responded well with mentality alert and improved general condition. He is now 28 months old and growing up well showing no symptoms of nausea, vomiting, seizures, or developmental delay. His regular followed-up has continued. Furthermore, until puberty, we have to continue checking him for hypogonadotropic hypogonadism $(\mathrm{HH})$.

\section{Discussion}

Primary adrenal failure is a lethal condition that can result from various etiologies. The cause of primary adrenal insufficiency in infants can be separated into congenital and acquired [6].

AHC is an adrenal developmental disorder. Congenital adrenal hyperplasia (CAH), caused by 21-OHD should be taken into account in the differential diagnosis of AHC. In the neonatal period, boys generally present signs and symptoms that are indistinguishable from those shown in the salt-losing form of 21-OHD. The serum concentration of 17-OHP is elevated in 21$\mathrm{OHD}$, but normal or low in $\mathrm{AHC}$. X-linked $\mathrm{AHC}$ is a rare disease with an incidence of 1:12,500 in the USA [7]. Diagnosing AHC is not always easy and can be overlooked if it is not considered in the differential diagnosis, in the context of adrenal crisis. Most patients present with failure to thrive, salt-wasting dehydration, hypoglycemia, and skin hyperpigmentation in the first month after birth. Glucocorticoid and mineralocorticoid replacement should be initiated. The $D A X 1$ gene has significance in adrenal development and function. Mutations in this gene may cause $A H C$, a rare cause of primary adrenal insufficiency in childhood
[8]. AHC is caused by mutations in DAX1 gene on the $X$ chromosome (Xp21). The DAX1 gene is expressed in various kinds of endocrine organs, and plays an important role in the maturation of the hypothalamic-pituitary-gonadal axis and the growth and development of the adrenal gland [2]. Genetic analysis of $D A X 1$ is significant male infants presenting with the salt-losing form of adrenal failure, when steroidogenic disorders, metabolic conditions, syndromes, autoimmune disease, infections and adrenal hemorrhage have been excluded. Because adrenal crisis is regarded as an endocrine emergency, early diagnosis induces an early treatment of hormonal replacement, reducing morbidity and preventing sudden death. In addition, a correct diagnosis is important for long-term treatment. The genetic locus for AHC mapped to Xp21.3 is the dosage sensitive sex reversal locus. Most missense mutations of the $D A X 1$ gene are on the C-terminal ligand-binding domain [9]. It has been reported that $D A X 1$ gene mutations are responsible for $\mathrm{AHC}$ in several papers. Most of the studied point mutations are stop or frameshift mutations producing a truncated nonfunctioning protein [10]. Some missense and deletion mutations in the DAX1 protein were identified [4]. There has been another report of $18 \mathrm{AHC}$ patients from 16 families whererin 6 patients were found to have gene deletions and 7 had point mutations in the $D A X 1$ gene [10]. Furthermore, AHC could be a part of a contiguous gene deletion syndrome which includes glycerol kinase deficiency (GKD) and Duchenne muscular dystrophy (DMD). Peter et al. [10] reported that those patients with a contiguous gene syndrome have deletions in the AHC-GKD-DMD gene locus, whereas most of the patients with isolated AHC (with $\mathrm{HH}$ ) had point mutations in the $D A X 1$ gene. It has been established that $D A X 1$ gene mutations play an important role in the frequent occurrence of $\mathrm{HH}$ in $\mathrm{AHC}$ patients. The most common pubertal disorder due to $A H C$, regarding $D A X 1$ gene mutation is the absence of or delay in puberty caused by disorders of the secretion of gonadotropin [11]. HH usually becomes apparent during adolescence even if the hypothalamic-pituitary-gonadal axis is usually intact in infancy. Other patients diagnosed with AHC in childhood, but not in the neonatal period, have been reported worldwide. In 2016, Davoodnejad et al. [12] reported 4 patients with AHC who were diagnosed in childhood. The most frequent initial symptoms of AHC patients were vomiting and poor feeding. In those patients, 2 missense mutations and 2 novel deletion mutations were found.

In our report, no previous family history of adrenal disorders or unexpected death in males were found. In such families, genetic study and counseling should be proposed for earlier 
treatment of their affected offspring. Our patient was found to have a nonsense mutation ( $\mathrm{A}$ for $\mathrm{C}$ at nucleotide 273 ) that resulted in a stop codon at position 91. In addition, during followup period, the patient had seizures due to hyponatremia caused by adrenal crisis. There were several case reports including longterm follow-up from initial diagnosis of AHC. One patient was a 5 -year-old boy who was diagnosed as AHC for the first time. His genomic DNA sequencing showed a hemizygous novel mutation - p.GIn282, c.844C>T in exon 1 of the NROB 1 gene, which creates a premature stop codon [13]. He, too, was treated with hydrocortisone and fludrocortisone. In this report, by the time he became 7 years old, he remained stable on follow-up and had no adrenal crisis at all. Another patient who was diagnosed as AHC in the neonatal period, presented with an episode of adrenal insufficiency at 7 months [8]. However, no other unexpected events had happened by the time he was 4-years-old. His DAX1 gene showed a frameshift mutation at codon 461 (pMet461Asp). Correlation between the various types of mutations of AHC and the severity of clinical symptoms of adrenal insufficiency caused by genetic factors, environmental and personal factors should be further studied.

In conclusion, we identified a novel nonsense mutation on the $D A X 1$ gene in a term Korean infant with congenital adrenal hypoplasia. This case highlights the significance of confirmatory genetic study of $D A X 1$ gene in adrenal insufficiency during the neonatal period.

\section{References}

1. Lehmann SG, Wurtz JM, Renaud JP, Sassone-Corsi P, Lalli E. Structure-function analysis reveals the molecular determinants of the impaired biological function of DAX-1 mutants in AHC patients. Hum Mol Genet 2003;12:1063-72.

2. Reutens $A T$, Achermann JC, Ito $M$, Ito $M, G u$ WX, Habiby $R L$, et al. Clinical and functional effects of mutations in the DAX-1 gene in patients with adrenal hypoplasia congenita. J Clin Endocrinol Metab 1999;84:504-11.
3. Metwalley KA, Farghaly HS. X-linked congenital adrenal hypoplasia associated with hypospadias in an Egyptian baby: a case report. J Med Case Rep 2012;6:428.

4. Nakae J, Tajima T, Kusuda S, Kohda N, Okabe T, Shinohara N, et al. Truncation at the $\mathrm{C}$-terminus of the DAX-1 protein impairs its biological actions in patients with $\mathrm{X}$-linked adrenal hypoplasia congenita. J Clin Endocrinol Metab 1996;81:3680-5.

5. Oelkers W, Diederich S, Bähr V. Diagnosis and therapy surveillance in Addison's disease: rapid adrenocorticotropin (ACTH) test and measurement of plasma ACTH, rennin activity, and aldosterone. J Clin Endocrinol Metab 1992;75:259-64.

6. Sperling MA. The adrenal cortex. Pediatric endocrinology. Pittsburgh: W.B. Saunders Company, 1996:301-5.

7. Achermann JC, Silverman BL, Habiby RL, Jameson JL. Presymptomatic diagnosis of $\mathrm{X}$-linked adrenal hypoplasia congenita by analysis of DAX1. J Pediatr 2000;137:878-81.

8. Mantovani RM, Pezzuti IL, Dias VMA, Silva IN. Identification of a novel mutation in DAX1/NROB1 gene in two siblings with severe clinical presentation of adrenal hypoplasia congenita. Arq Bras Endocrinol Metabol 2009;53:771-6.

9. Bae DS, Schaefer ML, Partan BW, Muglia L. Characterization of the mouse DAX-1 gene reveals evolutionary conservation of a unique amino-terminal motif and widespread expression in mouse tissue. Endocrinology 1996;137:3921-7.

10. Peter $M$, Viemann M, Partsch $C J$, Sippell WG. Congenital adrenal hypoplasia: clinical spectrum, experience with hormonal diagnosis, and report on new point mutations of the DAX-1 gene. J Clin Endocrinol Metab 1998;83:2666-74.

11. Park SH, Hong YH, Kim SS. Primary adrenal insufficiency in a newborn with adrenal hypoplasia congenita caused by a mutation of the DAX1 gene. Neonatal Med 2016;23:53-8.

12. Davoodnejad $M$, Eshraghi $P$, vakili $R$, Hamzehloie $T$. Identification of mutations in Iranian patients' DAX-1 gene with X-linked adrenal hypoplasia congenital. Egypt J Med Hum Genet 2017:18:165-72.

13. Abraham MB, Shetty VB, McKenzie F, Curran J. X-linked congenital adrenal hypoplasia with a novel NROB1/DAX gene mutation. Indian Pediatr 2016;53:529-31. 